MIDAS

Museus e estudos interdisciplinares

$2 \mid 2013$

Varia

\title{
Modos de ver e de dar a ver os Painéis de São
} Vicente

Ways of seeing and making visible the Saint Vincent Panels

Paula André, Luís Louzã Henriques, Luísa Isabel Martinho, Sónia Apolinário e Rui Reis Costa

\section{OpenEdition}

\section{Journals}

\section{Edição electrónica}

URL: http://journals.openedition.org/midas/256

DOI: $10.4000 /$ midas.256

ISSN: 2182-9543

\section{Editora:}

Alice Semedo, Paulo Simões Rodrigues, Pedro Casaleiro, Raquel Henriques da Silva, Ana Carvalho

\section{Refêrencia eletrónica}

Paula André, Luís Louzã Henriques, Luísa Isabel Martinho, Sónia Apolinário e Rui Reis Costa, « Modos de ver e de dar a ver os Painéis de São Vicente », MIDAS [Online], 2 | 2013, posto online no dia 03 abril 2013, consultado no dia 01 maio 2019. URL : http://journals.openedition.org/midas/256 ; DOI : $10.4000 /$ midas. 256

Este documento foi criado de forma automática no dia 1 Maio 2019.

\section{c) ()ㅇㅇㅣ}

Midas is licensed under a Creative Commons Attribution-NonCommercial-ShareAlike 3.0 International License 


\title{
Modos de ver e de dar a ver os Painéis de São Vicente
}

\author{
Ways of seeing and making visible the Saint Vincent Panels
}

Paula André, Luís Louzã Henriques, Luísa Isabel Martinho, Sónia Apolinário e Rui Reis Costa

\section{Introdução}

1 Sempre fizemos com o olhar o que hoje nos é apresentado como virtual. A pintura dos Painéis de São Vivente atribuídos a Nuno Gonçalves, é um espaço de ilusão real que exibe o seu potencial multisignificante, resistindo irredutível a qualquer leitura. o convite ao olhar feito pelos Painéis de São Vicente é um convite à investigação e às estratégias visuais que desvendam modos de ver e de dar a ver. As (re)criações artísticas feitas a partir desta obra são viagens do olhar que demonstram os mecanismos de criação e revelam os meios usados, criando novas realidades e novas verdades. Ver implica ver como se vê. Analisar as obras-mestras do passado consiste essencialmente em demonstrar o mecanismo da criação e revelar os meios usados (André 2008, 387). A prática da variação artística advém do confronto real com os mestres do passado, mas acima de tudo do prazer e da liberdade da criação. À semelhança de Harold Bloom que na sua obra Angústia da Influência, traçou uma genealogia de poetas fortes (Bloom 1991, 17), poderíamos através das variações artísticas traçar uma história dos pintores fortes, onde certamente encontraríamos Nuno Gonçalves. Os artistas que inovam estão profundamente ligados à tradição. João Vieira (1934-2009) realizou variações dos painéis atribuídos a Nuno Gonçalves. É o próprio pintor a dizer:

Como posso, simultaneamente, ser «absolutamente moderno» e admirar tanto pinturas antigas? Que quer isso dizer? Procurando respostas para estas perguntas, resolvi pintar à minha «maneira» pinturas antigas que me tocaram profundamente ao longo da minha vida. Para isso observei-as, tentando separar o essencial do acessório, procurando a verdade dessas pinturas, e ao mesmo tempo a verdade da minha própria pintura. Numa primeira tentativa, decidi-me pelos painéis de $\mathrm{S}$. 
Vicente, de Nuno Gonçalves, conhecidos como «o primeiro retrato coletivo do Renascimento Português»; apaguei as caras dos retratos, para pôr de lado abstrusas especulações identificatórias das personagens retratadas, tentando assim estabelecer a identidade do artista e a sua identificação com o País retratado (André 2008, 396).

2 Segundo Charles Sterling é na própria pintura «que permanece o segredo máximo dos Painéis e é no registo estético que o inquérito da História da Arte tem de o encontrar (Teixeira 1991, 360). Como refere José Luís Porfírio, a obra de João Vieira feita a partir dos Painéis de Nuno Gonçalves é

uma pintura que escreve (pinta) sobre outra pintura, muito mais velha, com quinhentos anos de idade e quatrocentos de esquecimento. É como uma ponte ou um salto, diz-nos que o passado pode estar aqui confrontado connosco, diz-nos que a pintura portuguesa do séc. XV pode FUNDAR HOJE uma vontade de fazer, uma vontade de dar mais pintura a Portugal! (Porfírio 1988, 7)

Interrogar "através do ato de pintar, [é] interrogar a sua própria arte de pintor" (Macedo 1988, 9). Tal como sublinhou André Malraux na sua obra O Museu imaginário (1947) muitas vezes o artista aponta os seus olhos não para o mundo ou para a vida mas para as obras dos criadores que o precederam. A nossa imaginação é a grande construtora da realidade virtual (André 2005, 41). A aplicação de software de edição e de animação de imagem para a elaboração e construção de conteúdos virtuais possibilitam novas formas de ver e de dar a ver a pintura. A utilização de técnicas avançadas de análise pictoral e espacial como motor de interpretação, e reveladas publicamente no site do Museu Nacional de Arte Antiga (MNAA), recorrendo às novas Tecnologias de Informação e Comunicação (TICs), devem potenciar o futuro contacto in situ com a obra, dando-se a obra a ver claramente vista, para usar uma expressão camoniana e confirmando que ver é ter visto usando uma expressão pessoana.

\section{1 - Os itinerários dos Painéis}

O ano de 1910 é marcado pela publicação do livro de José de Figueiredo "O pintor Nuno Gonçalves. Arte Portuguesa Primitiva" e pela primeira exposição dos Painéis de São Vicente na Academia Real das Belas-Artes, onde foram restaurados. De acordo com Sandra Leandro:

A descoberta científica dos painéis de S. Vicente deve-se a Joaquim de Vasconcelos, que no dia 20 de Julho de 1895 visitou aquele mosteiro acompanhado por Ramalho Ortigão, José Queiroz e o arcebispo de Mytilene. Antes de Joaquim de Vasconcelos, já Monsenhor Alfredo Elviro dos Santos, Leandro Braga, Columbano, Maria Augusta Bordalo Pinheiro e Alberto Henriques de Oliveira, entre outros, tinham notado a sua existência. A descoberta está envolvida também ela num mito, cujo lado trágicopicaresco recorda que, em 1882, os painéis foram salvos de servirem de tábuas de andaimes $(2008,258)$.

5 Sandra Leandro salienta ainda que "Maria João Baptista Neto, num artigo intitulado «A propósito da descoberta dos Painéis de São Vicente de Fora: contributo para o estudo e salvaguarda da pintura gothica em Portugal» desmonta, esclarece e elucida toda esta questão dando a palma a Mosenhor Alfredo Elviro dos Santos" (Leandro 2008, 258).

O conjunto de pinturas é em 1912 exposto no Museu Nacional das Belas-Artes, hoje MNAA, onde passou a residir desde então, como obra de referência. Durante um século de exibição, foram vários os critérios museográficos e vários os espaços habitados por esta 
obra, instaurando o conceito definido em 1951 por Martin Heidegger como "o sentido do ser", numa edificação que também se metamorfoseou a partir de uma estrutura palaciana inicial.

7 A investigação de José de Figueiredo então publicada permitirá ao seu autor operacionalizar os critérios expositivos dos painéis no MNAA, instituição onde chega em 1911 e dirige até 1937: a obra é exposta numa sala do andar nobre do palácio em dois trípticos (Couto 1948, 7 e 1959, 1). O mesmo critério tinha sido seguido na primeira exposição, e seria depois utilizado quando as pinturas viajaram para fora do país em 1929 e em 1931, respetivamente para a Exposição Cultural da Época dos Descobrimentos de Sevilha e para a Exposição Colonial Internacional de Paris (Couto 1957, 8; Couto 1956, 14)1. Sobre estas duas exposições diz nostalgicamente João Couto que "Nunca mais se fizeram certames de tanta importância, apresentados com tanto gosto e portadores de tão nobre mensagem" (Couto 1959, 1).

8 O ambiente expositivo do museu em 1911 era semelhante ao de tantos outros que herdaram do século XIX a tendência para a profusão de peças dispostas por toda a área das divisões, num espaço originalmente palaciano:

Nas portas interiores colocaram-se pesados reposteiros com suas guarnições. Ao passo que das paredes pendiam as pinturas, fixadas em várias filas, no centro das salas dispunham-se vitrines; e as cadeiras, mesas, baús, enfileiravam-se ao longo dos rodapés (Couto 1948, 6-7).

9 Contra este critério, José de Figueiredo decide expor apenas as obras com real valor artístico, e reduzir a quantidade de peças expostas, valorizando-as assim aos olhos do visitante. Seria um critério revolucionário.

10 Em 1940 inaugura-se o "Anexo" do MNAA com a exposição de Primitivos Portugueses. 1450-1550. Expostos no piso superior, os Painéis são apresentados em políptico numa parede forrada a tecido, e tendo um baldaquino gótico incorporado ao centro. Este critério segue a teoria de Almada Negreiros e do crítico de arte José de Bragança, de acordo com a qual a sequência das tábuas deveria respeitar a perspetiva dos ladrilhos ali representados. Após esta exposição coloca-se ao museu a decisão do critério a adotar doravante. Em 1942, diz o diretor João Couto:

expusemos as tábuas equidistantes, embora apresentando-as ordenadas da forma como a Exposição dos Primitivos as tinha exibido (...) Os organismos responsáveis do Estado não concordaram porém, com o nosso modo de ver. O Museu, foi de certo modo constrangido a subordinar-se ao critério da Exposição dos Primitivos se bem que simplificado, pois o dispensaram agora de colocar o baldaquino central para o São Vicente de vulto (Couto 1956, 9).

11 Assim, os Painéis manter-se-ão no "Anexo", mas numa solução mais sóbria que a do anterior diretor, pormenorizada apenas com algumas peças de mobiliário (Museografias 2008, 5).

12 Esta intervenção estatal é significativa da forma como no Estado Novo eram pensadas e tratadas as questões do património artístico, quando este era interpretado na perspetiva da identidade e glorificação nacionais. Os Primitivos Portugueses ocorrem numa data especialmente significativa para a nação, pois decorria a Exposição do Mundo Português. A exibição dos Painéis quer na referida exposição, quer enquanto obra central do Museu, dão a ver aquilo a que João Couto chama de o "lusitanismo da arte portuguesa", defendido por José de Figueiredo que, com a publicação da sua obra, teoriza a existência de uma escola portuguesa de pintura, até então desconhecida ou infundada. 
13 Em 1947 é celebrado o 8. centenário da tomada de Lisboa aos Mouros. O cortejo de celebração integra uma réplica de três dos Painéis, que desfilam até ao Rossio. Em 1955 a 3. e última viagem internacional dos Painéis cumpre-se até Londres, e o critério de incorporação de outras peças no centro do políptico, presente nos Primitivos Portugueses, é secundado.

14 Na XVII Exposição de Arte Ciência e Cultura, que o governo português organizou com o apoio do Conselho da Europa em 1983 sob a temática dos descobrimentos portugueses na Europa do Renascimento, o MNAA acolheu um dos cinco núcleos: A arte, ciência e cultura nos séculos XV e XVI. Aqui se reuniram aos Painéis, vindas de Espanha, as tapeçarias de Pastrana feitas a partir de cartões da autoria de Nuno Gonçalves, comemorativos da tomada de Arzila e da ocupação de Tânger. Este encontro de obras já tinha ocorrido pela primeira vez em 1929 em Sevilha, e voltará a acontecer em 2010.

O espaço do "Anexo" tem sido desde 1940 o local de exposição permanente dos Painéis. As referências das duas últimas décadas relativas aos critérios expositivos adotados para a obra denotam alguma diversificação sobre o espaço neutro que é atualmente a sua habitual ambiência, e ocorre em situações de exposições temporárias.

\section{2 - As variações e os Painéis}

Em 1988, num diálogo entre passado e presente, o MNAA expõe face a face os Painéis e as variações que o pintor João Vieira fez da obra de Nuno Gonçalves.

O próprio pintor faz questão de frisar:

apesar de todo o trabalho detectivesco feito à volta dos painéis ditos de Nuno Gonçalves, o «crime» permanece insolúvel. Os Painéis são tratados como meros documentos, como puzzles fotográficos, raramente como pintura que afinal são. Para procurar respostas decidi, não decifrar o «mistério dos painéis», mas criar uma obra a partir deles, que espero seja tão misteriosa, ou tão pouco, como eles são. Ponhamos que dou réplica à provocação do pintor - com outra pintura, como não pode deixar de ser. Assim encaro o problema da tradição: continuar a pintura, ou destrui-la, ou destruir-me (Vieira 1988, 41).

Em 2001 regressam temporariamente ao 2. andar do palácio, para a exposição Um Detalhe Imenso, em que fragmentos da capela das Albertas, reais ou representados, vêm povoar as salas do museu (Guelton 2001, 10). Se para alguns espaços se trazem objetos da capela, no caso da sala dos Painéis, aplicou-se um desenho mural de um pormenor arquitetónico. Em 2010 e em 2011, para as exposições A Invenção da Glória: D. Afonso V e as Tapeçarias de Pastrana, e, Primitivos Portugueses 1450-1550: o Século de Nuno Gonçalves, são adotados para o fundo em que surgem os Painéis cores fortes e quentes, respetivamente, vermelho e vinho. Na segunda, que assinala a comemoração de um século de exposição da obra, abrese um "diálogo com a contemporaneidade", colocando em frente aos painéis o retábulo contemporâneo "Altar Piece \#2" do pintor e escultor Pedro Cabrita Reis (Primitivos Portugueses 1450-1550. 2010, 5,7).

Subjacentes aos critérios expositivos estão determinadas políticas expositivas. Assim, sendo a obra de José de Figueiredo importante enquanto momento inicial de um "movimento lusitanista" na arte nacional, entende-se que em 1911 o seu autor passe a dirigir o MNAA e que os Painéis aí sejam acolhidos e tomados como obra de referência; na mesma lógica, os critérios expositivos adotados no museu serão secundados em exposições internacionais em que a glorificação e identidade nacionais - e coloniais ou 
imperiais - são uma das principais preocupações. Do mesmo modo a intervenção estatal no critério de exposição dos painéis após o evento do ano de 1940 se entende no sentido de não alterar a imagem que tinha sido dada a ver na Exposição do Mundo Português.

Também ao longo do tempo os sucessivos momentos de celebração nacional recorrem aos mesmos temas e obras. Os descobrimentos portugueses são recorrentemente celebrados, e com eles, as mesmas personalidades históricas, nomeadamente o Infante D. Henrique e Vasco da Gama, como se verificou na XVII Exposição e na Expo 98.

Quanto aos conceitos expositivos, verifica-se um percurso de despojamento dos critérios museográficos que, partindo de uma ambiência carregada de peças e elementos decorativos, caminha para uma simplificação progressiva do espaço, que acompanha o advento do modernismo e as subsequentes tendências artísticas. Assim, a profusão inicial encontrada por José de Figueiredo no museu segue um critério que, segundo O'Doherty (1999 [1976], 16), reporta a uma concatenação de períodos e estilos das obras que cobriam as paredes do chão ao teto, justificado pelas representações sociais da época:

o espaço era descontínuo e categorizável, do mesmo modo que as habitações que alojavam esses quadros tinham diferentes compartimentos para diferentes funções.

O pensamento do século XIX era taxonómico, e o olhar do século XIX reconhecia a hierarquia de estilos e a autoridade da moldura.

A depuração progressiva dos critérios caminha para um espaço neutro onde a obra de arte está isolada: de outras obras, e até do mundo para além das paredes do museu ou galeria, assemelhados a um cubo branco:

O mundo exterior não deve entrar, e assim, as janelas são habitualmente seladas. As paredes são pintadas de branco. $O$ tecto torna-se a fonte de luz. 0 chão de madeira polida percorre-se clinicamente, ou é alcatifado, apoio silencioso dos pés para que os olhos se dirijam para a parede (O’Doherty 1999 [1976], 15).

O "Anexo" onde desde 1940 os painéis têm permanecido presta-se a esta perspetiva, e pode mesmo dizer-se que a cumpriu e cumpre: paredes brancas, luz vinda do teto - onde antes houve luz zenital -, chão e rodapés discretos.

A confrontação da obra com as suas variações será um epifenómeno da reprodutibilidade da imagem que a fotografia permitiu quando surgiu no século XIX, e que iniciou um caminho sem volta na relação das obras com as suas reproduções, infinitas e imprevisíveis. Este fenómeno acaba por conferir à obra de arte não uma desvalorização, mas, um estatuto de sacralidade: "Se a imagem deixou de ser única e exclusiva, ao objeto de arte, à coisa, nada mais resta que transformar-se em objeto de mistério" (Berger 1972, 27). Esta "aura" de que Berger fala é perfeitamente enquadrável no espaço do cubo branco que encerra a obra, como que guardando uma relíquia intemporal. Deste modo, o MNAA mantém os painéis na sala branca que os exibe permanentemente, ao mesmo tempo que reproduz, no topo das fachadas do "Anexo", alguns dos rostos das personagens quinhentistas. A sacralidade da obra resguardada na sua célula convive com as reproduções dos rostos agigantados junto ao telhado, circundando o perímetro das fachadas do "Anexo".

O visual foi sempre importante nos museus e hoje em dia, numa sociedade onde predomina a cultura do visual, a utilização dos meios audiovisuais, torna-se atrativa num museu por ser familiar. Podem ser utilizados como complemento ao objeto em exposição ou substitui-lo. Pode ser integrado ao longo de uma exposição ou situar-se num local à parte. Permitem uma rápida atualização dos conteúdos, dando liberdade ao visitante de aceder ou não à informação (Delicado 2009, 469). 
desenvolvimento dos meios informáticos e o surgimento da internet, assim como as novas tendências museológicas, como a nova museologia, levou ao aumento do uso do multimédia digital nos museus (Delicado 2009, 469). 0 multimédia digital é o resultado da combinação de vários "media", texto, fotografia, gráficos, vídeo, áudio e animação, onde a informação pode ser representada, armazenada, transmitida e processada digitalmente, usando um computador (Fluckiger 1995, 5; Chapman e Chapman 2011, 7-11). No museu introduz novas formas de expor e de transmitir informação e altera a relação dos visitantes com o museu ao permitir a interatividade. Ao ser usado como complemento de uma exposição, facilita a transmissão da mensagem e dá pontos de vista diferentes aos objetos em exposição. Reinventa e populariza o museu tradicional repleto de objetos e textos, tornando a informação mais acessível, numa sociedade cada vez mais pluralista (Henning 2006, 302).

É neste contexto que a utilização da fotografia, como fonte documental pode ser utilizada. Desde o seu surgimento no século XIX, que a fotografia faz parte do nosso quotidiano. Ao reproduzir a realidade, adquire um caráter documental e imparcial, embora a imagem capturada retrate as opções do fotógrafo, as suas ideias, os seus modos de ver, assim como o que pretende transmitir. Com as evoluções tecnológicas e ao ser possível alterar, manipular as fotografias, o seu caráter documental pode ser posto em causa.

A memória liga o passado ao presente. A fotografia ao captar um momento imortaliza-o e permite recordá-lo, transmite uma representação, uma imagem do passado às novas gerações. Funciona como testemunho da verdade e justifica a "história", servindo de suporte à memória. As fotografias e desenhos que foram encontrados nos Arquivos e Biblioteca do MNAA, permitem documentar visualmente a informação escrita recolhida, permitindo visualizar os critérios expositivos de cada época, os diversos locais onde os painéis estiveram expostos, dentro e fora do museu e a disposição dos painéis. A realização de um filme utilizando essas fotografias e desenhos, permite visualizar o percurso dos Painéis durante estes 100 anos que se encontram em exposição. A sua integração no site do museu ou a sua utilização no interior do museu junto dos Painéis pode complementar a informação sobre estes, apresentando-os sob outra perspetiva, até agora ainda não abordada.

\section{3 - A paisagem e os Painéis}

A imagem deste retrato coletivo, ícone atemporal da nação, pode virtualmente viajar pelo território português, revelando a sua diversidade regional (Figura 1) e sublinhando os fundamentos da cultura portuguesa. A identidade nacional caracterizada pela diversidade regional motiva a contextualização da imagem dos Painéis na paisagem, promovendo a descoberta dos espaços rurais, e confirmando que "nenhuma coisa pode ser nacional se não é popular" (Garrett 1843, prefácio). A habitação de raiz popular e rural foi abordada por inúmeros estudiosos, arquitetos, antropólogos, geógrafos de variadas vertentes num processo em que era ela o fator de uma certa uniformidade da cultura popular, para rapidamente se tornar num símbolo de uma arquitetura mais funcionalista. Uma primeira geração de arquitetos do séc. XX aborda-a num enquadramento de um nacionalismo unificador de um todo nacional numa época em que curiosamente outros símbolos da identidade nacional reemergiam, nomeadamente a ideia de uma pintura especificamente nacional, sendo os Painéis de São Vicente o exemplo máximo desta singularidade. No entanto, uma nova abordagem de cariz antropológico, talvez a mais interessante, 
irrompia. A da casa vista como um instrumento produtivo. Como Ernesto Veiga de Oliveira, e Jorge Dias destacam que o interessante era o modo como ela funcionava no seio de um mundo específico, neste caso o mundo rural, como se ligava aos modos de vida das famílias e da comunidade em que se inseria. Mas também na sua paisagem. Um contributo decisivo na sistematização da diversidade regional desta arquitetura de acordo com os modelos assentes na divisão de um Portugal rural mediterrânico, atlântico e transmontano é proposto pelo geógrafo Orlando Ribeiro - a norte a casa de dois pisos, a sul casa de um só piso. O que aqui importa é um olhar sobre as bases e as condições materiais da vida rural e camponesa, um olhar para as diferentes tipificações da habitação como um instrumento agrícola que se adapta nas suas mais diversas variantes às necessidades e ao redimensionamento da exploração da terra com grande importância para os espaços específicos. José Mattoso realça que a influência das condições geográficas sobre a identidade nacional não se exprime apenas através de uma divisão regional mas também através de modalidades de ocupação e de organização do solo, de fatores físicos, como a altitude, o modelado e a natureza pedológica do solo como determinantes das condições climáticas, da facilidade ou dificuldade da circulação humana, da exploração da terra e do rendimento do trabalho agrícola.

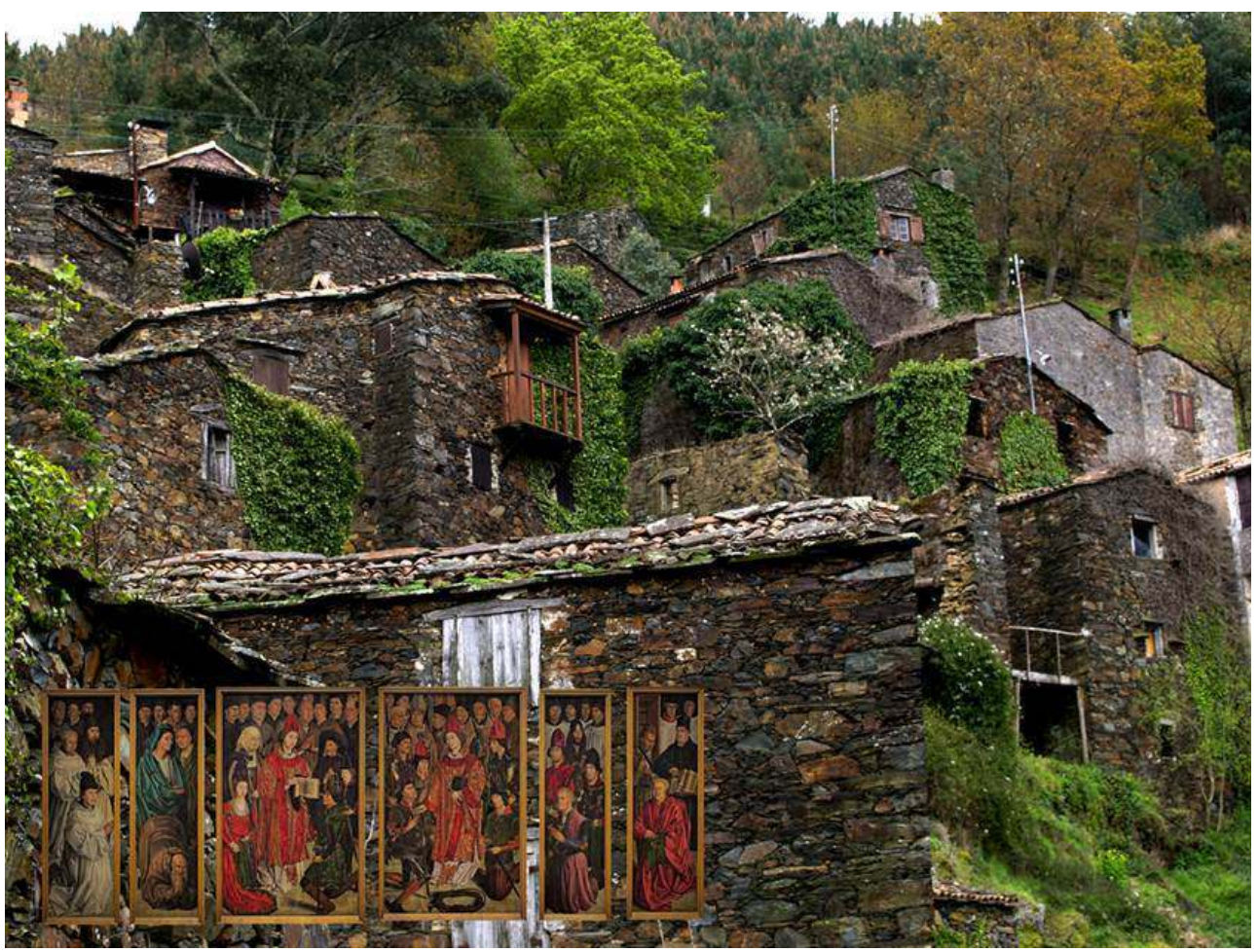

Figura 1 - fotomontagem: Painéis de São Vicente, sobre Serra da Lousã, Talasnal, casa de xisto. Painéis de São Vicente - Divisão de Documentação Fotográfica/IMC/José Pessoa. Fotografia de fundo de Luís Garção Nunes.

30 Hoje esta função social e económica perdeu-se com o desenvolvimento quer no meio rural quer no meio urbano. Uma situação que começou a alterar-se profundamente com o fenómeno da emigração na década de 60 do séc. XX. O fenómeno da emigração principalmente para Europa central trouxe influências culturais e arquitetónicas com novos desenhos de construção que nada tinham a ver com as características paisagísticas e climáticas das regiões portuguesas além da imediata e inevitável consequência da desertificação dos campos, despovoamento das terras e alteração na própria fisionomia 
da casa e da paisagem rural. Progressivamente uma arquitetura genuinamente popular começou a adquirir um estatuto com algum valor patrimonial num novo conceito que assume que o "Popular" não está só num mundo rural ou no passado. Antes, é produto de uma mistura de recursos e atores materiais e simbólicos. Nesta nova abordagem tem lugar o aprofundamento de práticas materiais e simbólicas intimamente interrelacionadas não só com a preservação e conservação mas também com a fruição turística. Um desses exemplos que tem tido bastante sucesso é a rede de "Aldeias de Xisto" projeto implementado na zona centro do País num total de 26 aldeias recuperadas em parceria com 21 municípios numa linha xistosa que vai desde Ferreira do Zêzere até à serra da Lousã, Açor, Arganil e Beira Baixa. E é aqui que radica esta proposta de fotomontagem: uma captação de imagens de um mundo rural de norte a sul do País, do litoral e do interior englobando a paisagem e a habitação rural numa viagem, roteiro, das casas do Minho, Trás-os-Montes, Douro interior, litoral, Beira Litoral, Beira Alta, Beira Baixa, Alentejo, Algarve e ilhas autónomas da Madeira e Açores. Na promoção turística destes espaços, com recurso a uma imagem e a um símbolo nacional (os Painéis de São Vicente) respeitando a diversidade de um território. Portugal, como Nação, território mais a Ocidente do Continente europeu, mais periférico e isolado de um Mundo antigo “(...) numa nesga de chão em grande parte bravio e ingrato, coube ao português o papel de pioneiro do Mundo Moderno" (Ribeiro 1998, 167). A problemática remete para um certo conceito de identidade Nacional e que ao longo dos Sec.(s) XIX e XX é sistematicamente tratada com um "excesso mítico de interpretação", um mecanismo entendido por Boaventura Sousa Santos como sendo de compensação do défice de realidade dos próprios produtores desta interpretação da falta de contacto com a realidade sociológica do País (Mattoso, cit. Santos 1992, 57).

31 Hoje, a sua singularidade em relação a outros países europeus advém do facto de na nova ordem mundial de globalização ser um País de desenvolvimento intermédio e semiperiférico. Provavelmente é esta singularidade que tem que ser captada também num certo modo de ver hoje um certo tipo de turismo, neste caso o rural direcionado para um segmento específico. E esgotada agora a função económica da atividade agrícola desses espaços, um dos possíveis caminhos seria o apelo ao turismo em espaço rural. Pretendeuse dar a conhecer nos dias de hoje, numa perspetiva turística um país riquíssimo no seu património histórico, arquitetónico, paisagístico e antropológico. Um país de uma unidade ímpar mas com uma diversidade espantosa. A proposta foi um projeto que seja capaz de atrair gente de dentro e de fora, procurando estabelecer uma unidade de um "Todo" nacional através destas imagens dos Painéis e a paisagem do território português. Uma unidade que se deve "em larga parte, ao predomínio destas regiões: elas constituem, no organismo nacional uma espécie de tronco antigo e robusto" (Ribeiro 1998, 166). Uma unidade de um povo simples que em muitas épocas e circunstâncias teve de partir, um país de viajantes mas também aquele dos que por cá ficaram. Nestes Painéis, está representada toda a sociedade portuguesa da época e ainda hoje é o reflexo de uma certa identidade nacional de várias origens sociais e proveniências regionais. É um "Ícone" e como tal permite uma reflexão individual ou coletiva assumindo uma dimensão social e antropológica podendo ser utilizada como imagem do país. Aqui estão representados rostos que ainda perduram neste território da Península Ibérica. Interrelacionando estas imagens caberá aqui uma nova abordagem de práticas materiais e simbólicas que permitem uma fruição turística a explorar. 


\section{4 - 0 virtual e os Painéis} realização de alguns exemplos, em que se utilizou o software da Adobe Photoshop (para o tratamento das imagens) e o da Adobe Flash (para a construção da animação). Deste modo, os Painéis de São Vicente podem ser apresentados de uma nova forma, a um "público virtual", através do site do museu. A utilização do software da Adobe não é gratuita, contudo, existem outros tipos de software que obtêm resultados idênticos, como o Pixlr ( http://pixlr.com/editor) ao invés do Adobe Photoshop e o Effect Generator (http:// www.effectgenerator.com) como alternativa ao Adobe Flash.

Os exemplos das imagens que se seguem demonstram o que se pode realizar de modo a introduzir conteúdos multimédia no site do museu. Na Figura 2, a imagem dos Painéis de São Vicente é exibida, contudo, ao passar com o rato por cima da imagem, da esquerda para a direita ou vice-versa, é desvendada uma outra pintura que contrasta com a seriedade e solenidade dos painéis do século XV: uma pintura naï a óleo de uma simplicidade bastante sugestiva e divertida, através da realizada pelo pintor francês Alain Donnat. Na Figura 3 é apenas representado um painel, o Painel do Infante, que oculta também uma outra pintura por detrás desta e do mesmo modo como na Figura 2, utilizamos a passagem do rato sobre a representação, revelando uma das variações mais conhecida dos painéis, assim como o seu autor, e que esteve em exposição na sala dos Passos Perdidos no MNAA, intitulada As imagens da escrita, realizada pelo pintor João Vieira em 1988. Nesta pintura, o pintor apaga conscientemente a cara às personagens, exprimindo a importância do conjunto sobre o singular. Fazendo deste modo referência as discussões que os especialistas possuíam sobre a identidade das personagens dos painéis. Finalmente a Figura 4 à semelhança da anterior esconde outra imagem e ao passarmos o rato sobre ela é deslindada uma das variações a partir dos painéis que desperta mais a curiosidade, realizada pelos alunos da disciplina de Educação Visual $e$ Tecnológica (EVT) do 5. ${ }^{\circ}$ ano da escola Artes CAD de 2007/08. Neste caso, cada aluno pintou em guache usando apenas cores primárias e secundárias (além do preto e branco) um fragmento do painel sem reconhecer aquilo que estava a pintar. Posteriormente, selecionaram-se os melhores fragmentos das três turmas de 5.․ ano que foram colados num painel de 150 x $100 \mathrm{~cm}$ criando esta variação artística.
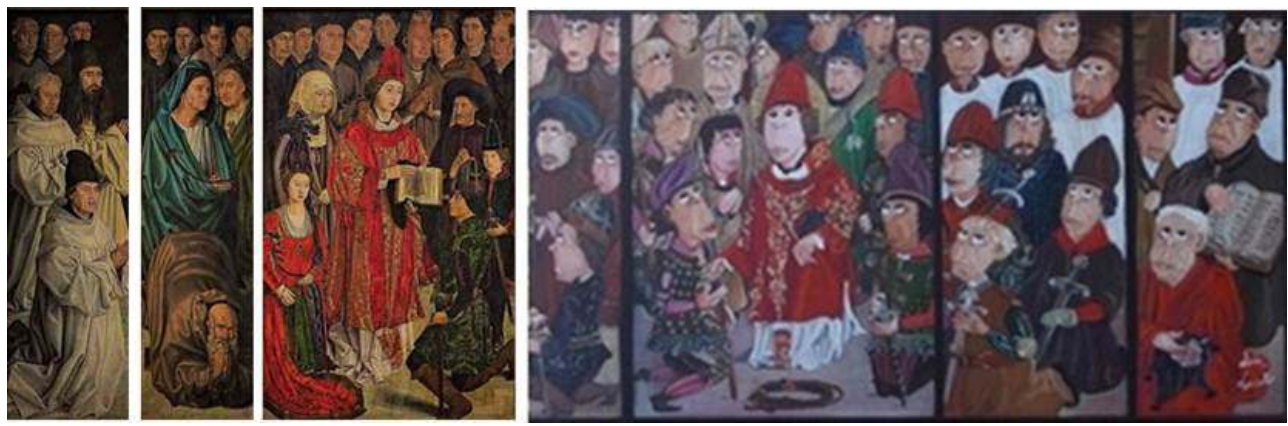

Figura 2 - À esquerda o Painel do Infante, Painéis de São Vicente; à direita os Painéis de São Vicente por Alain Donnat, 2010.

Painéis de São Vicente - Divisão de Documentação Fotográfica/IMC/José Pessoa. Imagem à direita retirada do site: http://allartsgallery.com/pt-PT/quadros/650-paineis-de-sao-vicente-by-alain-donnat? artist_id=71-alain-donnat-i 


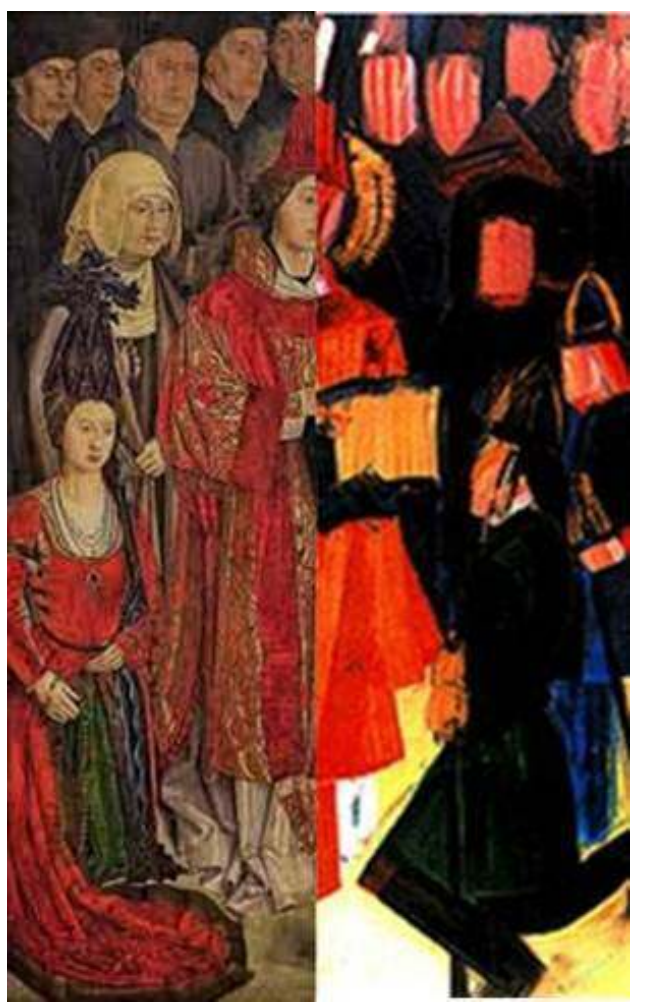

Figura 3 - À esquerda o Painel do Infante, Painéis de São Vicente; à direita o Painel do Infante da exposição "As imagens da escrita".

Painéis de São Vicente - Divisão de Documentação Fotográfica/IMC/José Pessoa. Imagem à direita da autoria de João Vieira, retirado do site: http://www.citi.pt/cultura/artes_plasticas/pintura/ joao_vieira/curricul.html 


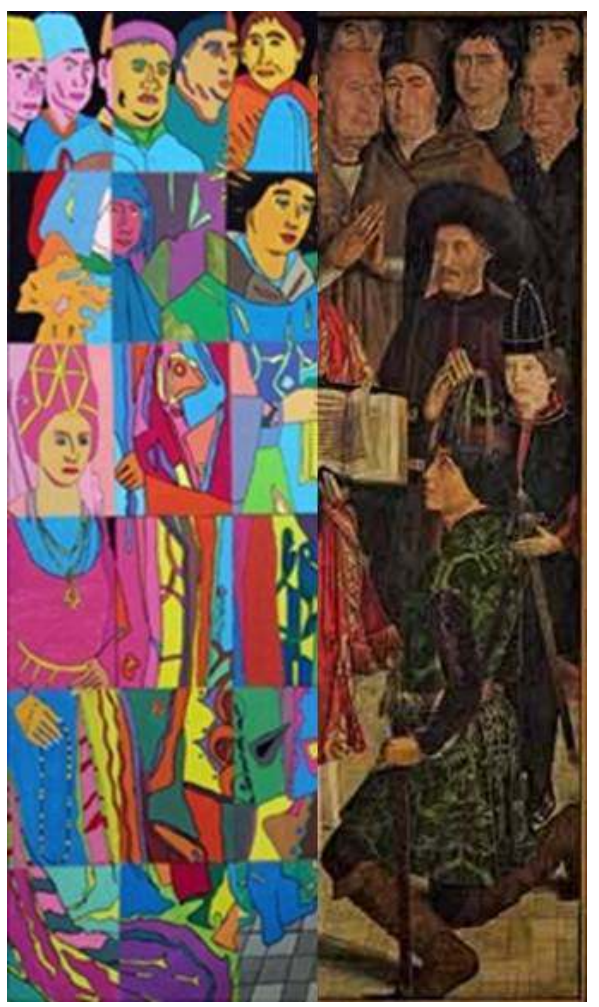

Figura 4 - À esquerda o Painel do Infante da autoria dos alunos de EVT do $5 .^{\circ}$ ano, 2007/08; à direita o Painel do Infante, Painéis de São Vicente.

Imagem à esquerda retirada do site http://artes.cad-cascais.org/?p=366. Panéis de São VicenteDivisão de Documentação Fotográfica/IMC/José Pessoa.

Outra realização de conteúdos, seria a adoção da Realidade Aumentada (AR), isto é, um sistema que combina elementos virtuais tridimensionais com elementos reais, desenvolvendo interatividade entre ambos em tempo real. Assim, do mesmo modo como acontece com o filme A Rosa Púrpura do Cairo, em que a personagem principal do filme interage com a espectadora dialogando e acabando por sair da própria tela, uma ou até várias personagens dos painéis, irão sair do painel e surpreender o visitante. Por exemplo, a figura de São Vicente fornecerá dados sobre a sua vida, ou a biografia do autor da obra Nuno Gonçalves, ou também sobre a discussão da ordem dos Painéis a que tão "apaixonadas polémicas se levantaram à roda desta notabilíssima obra" ${ }^{2}$, como afirmaria em 1942, o então diretor do MNAA, João Couto.

Recorrendo à tecnologia da Realidade Aumentada podemos fornecer aos visitantes do site do museu experiências singulares relacionadas com os Painéis de São Vicente.

Para criar a Realidade Aumentada, são necessários quatro elementos fundamentais:

1. objeto real que queremos transformar em objeto virtual.

2. Uma câmara que transmita a imagem do objeto real.

3. software que irá interpretar o sinal transmitido pela câmara.

4. dispositivo de saída que exibe o objeto virtual e a realidade sobrepostos num só.

As ferramentas mais utilizadas para criar a Realidade Aumentada são o ARToolKit e o Papervision3D, contudo, para quem não domina a Linguagem " $\mathrm{C}$ " ou o ActionScript, a criação de um objeto e sua animação não será tarefa fácil. 
De modo a que qualquer funcionário do museu, sem formação específica na área da programação, possa utilizar esta tecnologia para criação de conteúdos $A R$ no site do museu, sugere-se a utilização do EZFlar, um código OpenSource (código aberto), em ActionScript 3, tendo como base as ferramentas FLARManager, FLARToolkit e Papervision3D. Criado pelos brasileiros Eduardo Malpeli, Daniel Roda e Alex Freitas, o EZFlar pode ser assim utilizado por qualquer pessoa sem conhecimentos básicos de programação ao servir-se deste gerador de Realidade Aumentada online. É permitido a criação de objetos nos formatos de imagens (jpg, gif, png), no formato de vídeos Flash (swf, flv), no formato 3D - tridimensional (dae, md2) e no formato de som (mp3). Como se pode vislumbrar, as vantagens desta ferramenta é a sua acessibilidade, isto é, qualquer pessoa pode manuseála sem qualquer conhecimento prévio de programação, não ter qualquer custo associado ( OpenSource), e o facto de ser capaz de reconhecer os objetos para a realização da $A R$ em variados formatos.

39 A realização destes conteúdos irá possibilitar, de uma forma lúdica, o conhecimento através do site do museu, de obras de vários criadores contemporâneos, cujo ponto de partida foram os Painéis de São Vicente, e do modo como eles viram e interpretaram a obra quatrocentista. Estas novas oportunidades tecnológicas dão-nos a conhecer os Painéis vistos de outra forma, para além da obra atribuída a Nuno Gonçalves, e permitenos o seu relacionamento com a atualidade.

\section{Conclusão}

40 Sendo o conhecimento na sociedade contemporânea um "recurso-chave", é absolutamente necessário tornar a investigação académica num conhecimento produtivo, de modo a podermos alcançar a produtividade do conhecimento (André 2011, 702). Acreditamos que a parceria entre os agentes produtores de conhecimento histórico, os agentes produtores das novas TICs, e o museu, nomeadamente através de um acesso ágil a material existente nos seus arquivos e biblioteca, resultaria numa potencialização do trabalho académico tradicionalmente fechado na universidade e de acesso restrito aos investigadores e tornaria o conhecimento mais acessível e mais atrativo ao público em geral. Hans Belting, na sua obra A verdadeira imagem (2011), adverte que o nosso conceito de realidade altera-se constantemente, significando que também a nossa reivindicação de imagens se modifica, considera que a História da Arte deve alargar-se a uma História das Imagens que englobe a produção pré e pós-artística.

$41 \mathrm{Na}$ atual sociedade em rede, interconectada, as novas TICs, podem permitir através de dinâmicas de interacção, potenciar a comunicação com o público, expandindo a criação artística à escala global e promover a busca do essencial, desvendando o "sentido do ser", e cultivando a Quadratura. A revelação pública dos itinerários e das variações dos Painéis, assim como a manipulação da sua imagem icónica de forma atrativa e participada, promoverá um maior enraizamento territorial, e uma consciencialização do seu papel na cultura portuguesa. 


\section{BIBLIOGRAFIA}

André, Paula. 2005. "Ver Claramente Visto, Estratégias do Olhar. A Pintura como Palco Denotador da Imaginação”. Revista ArteTeoria. Revista dos Mestrado em Teorias da Arte 6:41-50.

André, Paula. 2008. “A Liç̧̃o da Pintura pela Pintura. Variações; Paráfrases; Apropriações; Citações". Varia Historia. Revista de Historia 25 (40):387-406.

André, Paula. 2011. “Do Conhecimento Histórico à Realidade Virtual. Revelar a Cidade". In 7VCT, 7th Virtual City and Territory Congress, 701-704. Lisboa: Universidade Nova de Lisboa.

Belting, Hans. 2011. A verdadeira imagem. Porto: Dafne.

Berger, John et al. 1972. Modos de ver. Lisboa: Edições 70.

Bloom, Harold. 1991. A Angústia da Influência. Lisboa: Edições Cotovia.

Canijo, João. 2010. Documentário "Fantasia Lusitana"; Extras, entrevista Realizador, DVD -Video, Lisboa: Periferia Filmes/Midas Filmes.

Chapman, Nigel e Jenny Chapman. 2011. Digital Multimedia. Chichester: John Wiley \& Sons Ltd.

Colocação das pinturas do Museu das Janelas Verdes. 1934. Volume I. Arquivo da Sala de Inventário do Museu Nacional de Arte Antiga.

Couto, João. 1941. “A exposição dos primitivos portugueses”. Boletim do Museu Nacional de Arte Antiga I (4):143-148.

Couto, João. 1948. “Justificação do arranjo de um Museu”. Boletim do Museu Nacional de Arte Antiga II (1):1-21.

Couto, João. 1956. “A pintura representada no Museu das Janelas Verdes e o critério da sua apresentação na galeria”. Boletim do Museu Nacional de Arte Antiga III (3):1-21.

Couto, João. 1957. “A pintura representada no Museu das Janelas Verdes e o critério da sua apresentação na galeria. II - As escolas estrangeiras”. Boletim do Museu Nacional de Arte Antiga III (4):1-9.

Couto, João. 1959. “José de Figueiredo". Boletim do Museu Nacional de Arte Antiga IV(2):1-6.

Delicado, Ana. 2009. A Musealização da Ciência em Portugal. Lisboa: Fundação Calouste Gulbenkian e Fundação para a Ciência e a Tecnologia.

Esquemas de distribuição das obras nas salas, até às grandes obras de transformação dos anos 1938-1943, Arquivo da Sala de Inventário do Museu Nacional de Arte Antiga.

Fluckiger, François. 1995. Understanding networked multimédia: applications and technology. Hertfordshire: Prentice Hall.

Freitas, Paula e Maria de Jesus Gonçalves.1987. Painéis de S. Vicente de Fora. Uma Questão Inútil? Lisboa: Imprensa Nacional - Casa da Moeda.

Garrett, Almeida. 1843. Romanceiro e Cancioneiro Geral. Lisboa: Typografia da Sociedade Propagadora dos Conhecimentos Úteis, Vol. I. prefácio.

Guelton, Bernard. 2001. Un Détail Immense. Lisboa: Museu Nacional de Arte Antiga. 
Heidegger, Martin. 2002. “Construir, Habitar, Pensar” In Ensaios e Conferências. Petrópolis: Vozes. Henning, Michelle. 2006. "New Media." In A Companion to Museum Studies, ed. Sharon Macdonald, 302-318. Oxford: Blackwell Publishing.

Henriques, Ana de Castro, ed. 2010. Primitivos Portugueses: 1450-1550. 0 século de Nuno Gonçalves. Lisboa: Museu Nacional de Arte Antiga.

João Vieira. Caretos II. 2006. Bragança: Museu do Abade de Baçal e Instituto Português de Museus. Leal, João. 2008. Arquitectos, Engenheiros e Antropólogos: Estudos na Arquitectura Popular no Séc. XX português. Porto: Fundação Marques da Silva.

Leandro, Sandra. 2008. Joaquim de Vasconcelos (1849-1936). Historiador, Crítico de Arte e Museólogo. Tese de doutoramento, Faculdade de Ciências Sociais e Humanas -Universidade Nova de Lisboa. Macedo, Helder. 1988. “Quadros por Letras” In João Vieira. As imagens da escrita. Lisboa: Museu Nacional de Arte Antiga.

Malraux, André. 1947. O Museu Imaginário. Lisboa: Edições 70.

Museografias. 2008. Lisboa: Museu Nacional de Arte Antiga.

Neto, Maria. 2003. “A propósito da descoberta dos Painéis de São Vicente de Fora. Contributo para o estudo e salvaguarda da pintura gothica em Portugal". Artis. Revista do Instituto de História da Arte da Faculdade de Letras de Lisboa 2:219-260.

Nuno Gonçalves: Novos documentos: estudo da Pintura Portuguesa do Séc. XV. 1994. [Lisboa]: Instituto Português de Museus.

O’Doherty, Brian. 1999 [1976]. Inside the White Cube. The Ideology of the Gallery Space. Los Angeles: University of California Press.

O Museu das Janelas Verdes. 1995 [1987]. Lisboa: Museu Nacional de Arte Antiga.

Porfírio, José Luís. 1988. “Escrever sobre...”. In João Vieira. As imagens da escrita. Lisboa: Museu Nacional de Arte Antiga.

Portugal em Sevilha. Catálogo da Exposição Cultural Descobrimentos. 1929. Lisboa: Museu Nacional de Arte Antiga.

Portuguese Art. (800-1800). 1955. London: Royal Academy of Arts.

Primitivos Portugueses. 1940. Lisboa: Museu das Janelas Verdes.

Primitivos Portugueses 1450-1550. O Século de Nuno Gonçalves. 2010. Lisboa: Museu Nacional de Arte Antiga.

Primitivos Portugueses 1450-1550. o Século de Nuno Gonçalves. 2010. Lisboa:

Museu Nacional de Arte Antiga.

Ribeiro, Orlando. 1998. Portugal o Mediterrâneo e o Atlântico. Lisboa: Livraria Sá da Costa.

Roteiro das Pinturas. 1956. Lisboa: Museu Nacional de Arte Antiga.

Encompassing the Globe: Portugal and the World in the $16^{\text {th }}$ and $17^{\text {th }}$ centuries. 2007. Washington: Smithsonian Institute.

Teixeira, José Carlos da Cruz. 1991. A Pintura Portuguesa do Renascimento. Ensaio de Caracterização. Tese de doutoramento, Faculdade de Ciências Sociais e Humanas -Universidade Nova de Lisboa. Vieira, João. 1988. “As Imagens da Escrita” In João Vieira. As imagens da escrita. Lisboa: Museu Nacional de Arte Antiga. 
Vieira, João. 2008. Texto inédito.

\section{ANEXOS}

Webgrafia:

Mattoso, José. A Identidade Nacional. http://www.ebah.com.br/content/ABAAAAMQYAD/ a-identidade-nacional (consultado em março 18, 2012)

Museu Nacional de Arte Antiga. 2012 “História”. Última atualização 15 março, http:// www.mnarteantiga-ipmuseus.pt/pt-PT/edificio/historia/ContentDetail.aspx?id=385. (consultado em março 18, 2012)

A Rosa Purpura do Cairo http://www.youtube.com/watch?v=LXi6xsq_dYs (consultado em março 18, 2012)

Painel do Infante (EVT 5a ano, 2007/08) http://artes.cad-cascais.org/?p=366 (consultado em março 18, 2012)

Painéis de São Vicente por Alain Donnat http://allartsgallery.com/pt-PT/quadros/650paineis-de-sao-vicente-by-alain-donnat?artist_id=71-alain-donnat-i (consultado em março 18, 2012)

Painel do Infante por João Vieira (As imagens da escrita) http://www.citi.pt/cultura/ artes_plasticas/pintura/joao_vieira/curricul.html (consultado em março 18, 2012)

Painéis de S. Vicente de Fora http://paineis.org/INDICE.htm (consultado em março 18, 2012) Aldeias do Xisto http://www.aldeiasdoxisto.pt (consultado em março 18, 2012)

\section{NOTAS}

1. É referido no Roteiro das Pinturas (1956, prefácio da 2. edição) que os painéis estiveram na Exposição de Bordéus, no entanto não foram encontrados mais dados que o confirmassem.

2. Ofício da Direção dos Museus Nacionais de Arte Antiga à Direção Geral do Ensino Superior e das Belas Artes redigido pelo Diretor do Museus nacionais de Arte Antiga, João Rodrigues da Silva Couto, Lisboa 28 de abril de 1942, 123-124.

\section{RESUMOS}

O artigo Modos de ver e de dar a ver os Painéis de São Vicente centra-se na ideia de que o conhecimento histórico articulado com as novas tecnologias pode ser uma forma de apropriação e de afirmação da pintura e da cultura portuguesa. A análise e a perceção dos contextos que determinaram os sucessivos percursos espaciais dos Painéis dentro e fora do Museu Nacional de 
Arte Antiga (Lisboa) e das sucessivas variações artísticas, assim como a manipulação virtual da imagem icónica dos Painéis na paisagem portuguesa, ou em realidades virtuais podem revelar a pintura de forma expressiva, pública e à escala global e contribuir para uma apreensão efetiva e afetiva dos fundamentos da cultura portuguesa. 0 museu como espaço identitário por excelência deve construir ferramentas que potenciem esta apreensão, inovando nos sistemas de divulgação, trabalhando em parceria com os agentes produtores de investigação na área do conhecimento histórico e na área das realidades virtuais, construindo formas instigantes de ver e ler a pintura.

The paper Ways of seeing and making visible the Saint Vincent Panels focuses on the idea that articulating historical knowledge with new technologies can be a form of ownership and statement for Portuguese culture and painting. Analyzing and understanding the contexts that established the successive spatial trajectories of the panels inside and outside the Museu Nacional de Arte Antiga (Lisbon), and the successive artistic variations, as well as the virtual manipulation of the iconic image of panels in the Portuguese landscape or in virtual realities, can show the painting in an expressive way, publicly and globally, and contribute to an effective and affective grasp of the fundamentals of Portuguese culture. The museum, as a space of identity par excellence, should build tools that enhance this understanding, innovating in disclosure systems and working in partnership with agents to produce research on historical knowledge in the area of virtual realities, producing thought-provoking/exciting ways to see and read the painting.

\section{ÍNDICE}

Keywords: National Museum of Ancient Art, information and communications Technology, Saint Vincent Panels, virtual

Palavras-chave: Museu Nacional de Arte Antiga, Painéis de São Vicente, tecnologias da informação e da comunicação, virtual

\section{AUTORES}

\section{PAULA ANDRÉ}

Doutorada em Arquitetura e Urbanismo, professora do Departamento de Arquitetura e Urbanismo do ISCTE-IUL, e coordenadora das Unidades Curriculares: História da Arquitetura e da Cidade I e II, Teoria da Arquitetura Contemporânea I e Lisboa: Ruturas e Continuidades (Mestrado Integrado em Arquitetura); História e Teoria da Arquitetura (Mestrado em História Moderna e Contemporânea: Cidades e Património); Arquitetura de Museus (Mestrado em Museologia). Membro efetivo do Centro de Estudos sobre a Mudança Socioeconómica e o Território (DINAMIACET); Membro do Laboratório de Habitação (LAB HAB; ISCTE-IUL); Membro da Direção do Centro de Estudos Urbanos (CEURBAN); Membro da Rede Portuguesa de Morfologia Urbana (PNUM). paula.andre@iscte.pt

\section{LUÍS LOUZÃ HENRIQUES}

Nasceu em Coimbra em 1971. Licenciado em Sociologia pela Faculdade de Economia da Universidade de Coimbra com conclusão do seminário de investigação em "Sociologia do Poder e da Política”. Trabalha nos Bairros Municipais de Lisboa, exercendo a função de técnico de intervenção social desde 2001. Tem a pós-graduação do curso de Museologia "Conteúdos Expositivos" no ISCTE-Instituto Universitário de Lisboa (ISCTE-IUL). É atualmente aluno de mestrado do mesmo curso. llhenriques@gmail.com 


\section{LUÍSA ISABEL MARTINHO}

Nasceu em Lisboa a 12 de julho de 1966. É licenciada em História Moderna e Contemporânea (2010) pelo ISCTE-Instituto Universitário de Lisboa (ISCTE-IUL), tendo feito uma pós-graduação em "Museologia: Conteúdos Expositivos" (2011) também no ISCTE-IUL. Interessa-se pela participação de Portugal na 1. Guerra Mundial, encontrando-se a escrever a dissertação de mestrado sobre "Portugal na Primeira Guerra Mundial: A vida nas trincheiras. Uma abordagem multimédia". Trabalha como administrativa nos Serviços Municipalizados de Loures desde 1990. isabelmartinho1@gmail.com

\section{SÓNIA APOLINÁRIO}

Natural de Lisboa, licenciada em Sociologia em 1999 pelo ISCTE-Instituto Universitário de Lisboa (ISCTE-IUL), onde foi doutoranda em Sociologia entre 2004 e 2007. Trabalhou no Observatório das Ciências e Tecnologias, e num gabinete técnico no ISCTE-IUL até 2011. Atualmente está a concluir o Mestrado em "Museologia: Conteúdos Expositivos", também no ISCTE-IUL, tendo em 2010-2011 terminado a pós-graduação com a mesma designação. soniapiedadeapolinario@gmail.com

\section{RUI REIS COSTA}

Licenciado em História pela Universidade Lusíada em 2002. Atualmente a trabalhar como Assistente-Técnico no Museu Nacional do Traje (Portugal). ruireiscosta@gmail.com 